\title{
Does the Diagnosis of Pulmonary Contusions Really Matter in the Modern ICU?
}

Pulmonary contusions are the end result of pulmonary parenchymal injury, specifically hemorrhage, which results in the radiographic appearance of consolidation and collapse on plain radiographs or computed tomographies. The majority of pulmonary contusions are the end result of external mechanical forces on the bony thoracic wall that causes mechanical injury to the underlying lung due to displacement of fractured ribs or direct compression of the chest wall. ${ }^{1}$ Hemorrhage at the site of parenchymal injury is followed by interstitial edema and inflammatory cell infiltration as early as $1-2 \mathrm{~h}$ after trauma. The ensuing inflammatory cascade leads to destruction of the pulmonary architecture by massive edema and the filling of the air spaces by red and white blood cells, cellular debris, and proteins over the next $24-48 \mathrm{~h}^{2}{ }^{2}$ Historically, this lung "bruising" has been associated with negative pulmonary outcomes, which include hypoxemia, pneumonia, and ARDS. Previous groups have described a linear relationship between the extent of the contusion seen on chest imaging and the severity of pulmonary disease. ${ }^{3}$ Nonetheless, through supportive care, the great majority of pulmonary contusions resolve by 7 days after injury.

In this issue of RESPIRATORY CARE, Dhar et $\mathrm{al}^{4}$ investigated the effects of pulmonary contusions in 163 severely injured trauma subjects (chest abbreviated injury scale of $\geq 3$ ), who required mechanical ventilation for at least $24 \mathrm{~h}$. Of the cohort, $>50 \%$ had pulmonary contusions identified by plain chest radiography and adjudicated by unanimous agreement of 3 blinded reviewers. Subject demographics, injury severity, and resuscitation characteristics (blood products and daily fluid balances) were well matched between those with and those without pulmonary contusions. Hospital mortality, discharge disposition, tracheostomy rates, mechanical ventilator utilization, and ventilator-associated events did not differ between the groups. However, those with pulmonary contusions were more likely to have ventilator-associated pneumonia with methicillin-sensitive Staphylococcus aureus, whereas

\footnotetext{
Dr Robinson reports no conflicts of interest.
}

Correspondence: Bryce R H Robinson MD MSc, Department of Surgery, University of Washington, Harborview Medical Center, 325 9th Ave Seattle, WA 98104. E-mail: brobinso@uw.edu.

DOI: $10.4187 /$ respcare. 06388 those without a contusion were more likely to grow Pseudomonas aeruginosa. The clinical importance of these results is difficult to interpret given the relatively low number of these events throughout the study cohort.

See the Original Study on Page 950

Modern pulmonary critical care, as applied to patients who are injured, centers around the prevention of secondary, iatrogenic injury. The controversy of an appropriate resuscitation in those with a contusion has existed since Burford and Burbank ${ }^{5}$ described wet lungs in those with aggressive resuscitations and thoracic injuries during World War II. Unfortunately, few clinical trials exist that define the consequences of various resuscitation techniques for those with a contusion, and animal models have been inconclusive. $^{6-9}$ Resuscitation practices have dramatically evolved over the past 15 years due to advances in military medicine from the conflicts in southwest Asia. Damage control resuscitation, with an emphasis on balanced blood component therapy and the avoidance of crystalloids, is the standard of care for those with active hemorrhage in both military and civilian trauma practices. ${ }^{10-12}$

Early concerns were raised about transfusion-related acute lung injury with the widespread use of balanced component therapy, specifically, higher ratios of plasma and platelets during damage control resuscitation. ${ }^{13} \mathrm{Sec}-$ ondary analyses of large, prospective trials of subjects severely injured and with hemorrhage have demonstrated early crystalloid exposure, and not blood, as an independent factor for the development of lung injury and ARDS during the first week of care. ${ }^{14,15}$ Crystalloid exposures seem to be minimized in the current work. The investigators describe a daily fluid balance of $627-669 \mathrm{~mL}$ between the cohorts. ${ }^{4}$ This is a relatively restrictive volume given that this also includes fluid provided during an average of 2 operations per subject. In contrast, blood product exposures seem common and high, with subjects receiving, on average, $>800 \mathrm{~mL}$ of blood. ${ }^{4}$ With crystalloid minimized and blood component therapy emphasized, one would expect the effects of pulmonary contusion to be negligible in the current era of damage control resuscitation with crystalloid minimization. 
Since the publication of the seminal ARDSnet trial, ${ }^{16}$ the application of lung-protective ventilation has expanded to include those patients without clinical lung injury but at risk for it, in an effort to mitigate secondary injury by iatrogenic volutrauma. ${ }^{16,17}$ A lower pulmonary infection rate and duration of hospital stay has been associated with the application of lung-protective ventilation in those without ARDS. ${ }^{18}$ In the era in which large pulmonary contusions were closely associated with pulmonary derangements, a minority of patients had lung protective tidal volumes applied before the diagnosis of ARDS. ${ }^{19,20}$ Current practice has dramatically changed. In a recent large, multi-center, multinational trial of critically ill subjects without ARDS at the onset of mechanical ventilation, the median tidal volume was $7.9 \mathrm{~mL} / \mathrm{kg}$ of predicted body weight. ${ }^{21}$ Approximately, $70 \%$ of the population had median tidal volumes of $<8.0 \mathrm{~mL} / \mathrm{kg}$ of predicted body weight. Dhar et $\mathrm{al}^{4}$ follow this same practice pattern. Those with a pulmonary contusion had a mean tidal volume of $7.5 \mathrm{~mL} / \mathrm{kg}$ of predicted body weight versus $7.2 \mathrm{~mL} / \mathrm{kg}$ in those without. The investigators of the current study seem to present subjects with lung-protective ventilation, which likely adds to the mitigation of hypoxemia in those with significant chest injury. ${ }^{4}$

Although not reported by the investigators, critical care pain and sedation practices have also dramatically evolved over the past decade. Aggressive analgesia for thoracic wall injury, specifically rib fractures, attempts to restore pulmonary mechanics to reduce the spiral from hypoventilation with atelectasis to pulmonary decompensation. When possible, regional analgesia techniques are favored over systemic narcotics because they may exacerbate poor secretion clearance secondary to their sedative properties. ${ }^{22}$ The placement of epidural catheters in trauma patients with multiple rib fractures is associated with significant reductions in the rate of pneumonia and ventilator utilization. ${ }^{23}$ Whether with regional anesthesia, multimodal pain control, involvement of hospital-based acute pain services, or early mobilization efforts, aggressive critical care management of patients with thoracic wall injury reduces negative pulmonary outcomes that were common in years past.

The retrospective work of Dhar et $\mathrm{al}^{4}$ provides evidence that pulmonary contusions contribute little to negative outcomes. Supportive care is drastically different today than in years past, when the negative consequences were first described. As with most care bundles, it is difficult to delineate the most beneficial component because maximal benefit is likely the result of all practiced in concert. Future, prospective work should aim to define the contribution of up-to-date resuscitation, mechanical ventilation, and analgesia practices in this commonly encountered traumatic injury.
Bryce R H Robinson MD MSc

Department of Surgery

University of Washington

Harborview Medical Center

Seattle, Washington

\section{REFERENCES}

1. Cohn SM, Dubose JJ. Pulmonary contusion: an update on recent advances in clinical management. World J Surg 2010;34(8):19591970.

2. Fulton RL, Peter ET. The progressive nature of pulmonary contusion. Surgery 1970;67(3):499-506.

3. Tyburski JG, Collinge JD, Wilson RF, Eachempati SR. Pulmonary contusions: quantifying the lesions on chest X-ray films and the factors affecting prognosis. J Trauma 1999;46(5):833-838.

4. Dhar SM, Breite MD, Barnes SL, Quick JA. Pulmonary contusion in mechanically ventilated patients after severe trauma. Respir Care 2018;63(8):950-954.

5. Burford TH, Burbank B. Traumatic wet lung; observations on certain physiologic fundamentals of thoracic trauma. J Thorac Surg 1945; 14:415-424.

6. Richardson JD, Woods D, Johanson WG Jr, Trinkle JK. Lung bacterial clearance following pulmonary contusion. Surgery 1979;86(5): 730-735.

7. Richardson JD, Franz JL, Grover FL, Trinkle JK. Pulmonary contusion and hemorrhage-crystalloid versus colloid replacement. J Surg Res 1974;16(4):330-336.

8. Fulton RL, Peter ET. Physiologic effects of fluid therapy after pulmonary contusion. Am J Surg 1973;126(6):773-777.

9. Rutherford RB, Valenta J. An experimental study of "traumatic wet lung". J Trauma 1971;11(2):146-166.

10. Holcomb JB, Jenkins D, Rhee P, Johannigman J, Mahoney P, Mehta $\mathrm{S}$, et al. Damage control resuscitation: directly addressing the early coagulopathy of trauma. J Trauma 2007;62(2):307-310.

11. Cannon JW, Khan MA, Raja AS, Cohen MJ, Como JJ, Cotton BA, et al. Damage control resuscitation in patients with severe traumatic hemorrhage: A practice management guideline from the Eastern Association for the Surgery of Trauma. J Trauma Acute Care Surg 2017;82(3):605-617.

12. Butler FK, Holcomb JB, Schreiber MA, Kotwal RS, Jenkins DA, Champion HR, et al. Fluid Resuscitation for Hemorrhagic Shock in Tactical Combat Casualty Care: TCCC Guidelines Change 14-01-2 June 2014. J Spec Oper Med 2014;14(3):13-38.

13. Silliman CC, McLaughlin NJ. Transfusion-related acute lung injury. Blood Rev 2006;20(3):139-159.

14. Robinson BR, Cotton BA, Pritts TA, Branson R, Holcomb JB, Muskat $\mathrm{P}$, et al; the PROMMTT study group. Application of the Berlin definition in PROMMTT patients: the impact of resuscitation on the incidence of hypoxemia. J Trauma Acute Care Surg 2013;75(1 Suppl 1):S61-S67.

15. Robinson BRH, Cohen MJ, Holcomb JB, Pritts TA, Gomaa D, Fox $\mathrm{EE}$, et al. Risk factors for the development of acute respiratory distress syndrome following hemorrhage. Shock 2017. [Epub ahead of print].

16. Acute Respiratory Distress Syndrome Network, Brower RG, Matthay MA, Morris A, Schoenfeld D, Thompson BT, Wheeler A. Ventilation with lower tidal volumes as compared with traditional tidal volumes for acute lung injury and the acute respiratory distress syndrome. N Engl J Med 2000;342:1301-1308.

17. Lellouche F, Lipes J. Prophylactic protective ventilation: lower tidal volumes for all critically ill patients? Intensive Care Med 2013; 39(1):6-15. 


\section{EDITORIALS}

18. Serpa Neto A, Cardoso SO, Manetta JA, Pereira VG, Espósito DC, Pasqualucci Mde O, et al. Association between use of lung-protective ventilation with lower tidal volumes and clinical outcomes among patients without acute respiratory distress syndrome: a meta-analysis. JAMA 2012;308(16):1651-1659.

19. Miller PR, Croce MA, Bee TK, Qaisi WG, Smith CP, Collins GL, Fabian TC. ARDS after pulmonary contusion: accurate measurement of contusion volume identifies high-risk patients. J Trauma 2001; 51(2):223-228; discussion 229-230.

20. Mizushima Y, Hiraide A, Shimazu T, Yoshioka T, Sugimoto H. Changes in contused lung volume and oxygenation in patients with pulmonary parenchymal injury after blunt chest trauma. Am J Emerg Med 2000;18(4):385-389.
21. Neto AS, Barbas CSV, Simonis FD, Artigas-Raventós A, Canet J, Determann RM. Epidemiological characteristics, practice of ventilation, and clinical outcome in patients at risk of acute respiratory distress syndrome in intensive care units from 16 countries (PRoVENT): an international, multicentre, prospective study. Lancet Respir Med 2016;4(11):882-893.

22. Galvagno SM Jr, Smith CE, Varon AJ, Hasenboehler EA, Sultan S, Shaefer G, et al. Pain management for blunt thoracic trauma: A joint practice management guideline from the Eastern Association for the Surgery of Trauma and Trauma Anesthesiology Society. J Trauma Acute Care Surg 2016;81(5):936-951.

23. Bulger EM, Edwards T, Klotz P, Jurkovich GJ. Epidural analgesia improves outcome after multiple rib fractures. Surgery 2004;136(2):426-430. 